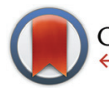

CrossMark $\leftarrow$ click for updates

Cite this: Dalton Trans., 2016, 45 7941

Received 12th March 2016, Accepted 15th April 2016

DOI: $10.1039 / c 6 d t 00978 f$

www.rsc.org/dalton

\title{
A multi-step solvent-free mechanochemical route to indium(III) complexes $\uparrow$
}

\author{
Jingyi Wang, ${ }^{a}$ Rakesh Ganguly, ${ }^{a}$ Li Yongxin, ${ }^{a}$ Jesus Díaz, ${ }^{b}$ Han Sen Soo* ${ }_{+}^{+}, c, d$ and \\ Felipe García* $\ddagger^{a}$
}

\begin{abstract}
Mechanochemistry is well-established in the solid-phase synthesis of inorganic materials but has rarely been employed for molecular syntheses. In recent years, there has been nascent interest in 'greener' synthetic methods with less solvent, higher yields, and shorter reaction times being especially appealing to the fine chemicals and inorganic catalyst industries. Herein, we demonstrate that main-group indium(III) complexes featuring bis(imino) acenaphthene (BIAN) ligands are readily accessible through a mechanochemical milling approach. The synthetic methodology reported herein not only bypasses the use of large solvent quantities and transition metal reagents for ligand synthesis, but also reduces reaction times dramatically. These new main-group complexes exhibit the potential to be reduced to indium(l) compounds, which may be employed as photosensitizers in organic catalyses and functional materials.
\end{abstract}

Mechanochemistry refers to a branch of predominant solidstate processes, in which reactions can be induced by mechanical energy, through grinding, shearing, and ball milling for instance. ${ }^{1}$ Mechanochemical techniques have historically been mostly applied in the solid-phase syntheses of poorly soluble metal oxides, ceramics, ${ }^{2}$ and alloys, ${ }^{3}$ but have increasingly been adopted in modern fields such as nanomaterials. ${ }^{4}$ Despite some seminal work on cocrystallization of organic compounds in the $1980 \mathrm{~s},{ }^{5}$ there has not been widespread adoption of mechanochemistry in synthetic organometallic chemistry and catalytic reactions until some recent reports on

\footnotetext{
${ }^{a}$ Division of Chemistry and Biological Chemistry, School of Physical and Mathematical Sciences, Nanyang Technological University, 21 Nanyang Link 637371, Singapore.E-mail: hansen@ntu.edu.sg, fgarcia@ntu.edu.sg

${ }^{b}$ Departamento de Quimica Orgánica e Inorgánica, Facultad de Veterinaria, Universidad de Extremadura, Cáceres 10071, Spain

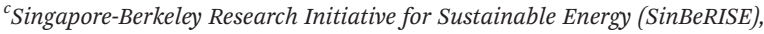

1 Create Way, Singapore 138602

${ }^{d}$ Solar Fuels Laboratory, Nanyang Technological University, 50 Nanyang Avenue, Singapore 639798

$\dagger$ Electronic supplementary information (ESI) available. CCDC 1439070 and 1439071. For ESI and crystallographic data in CIF or other electronic format see DOI: $10.1039 / \mathrm{c} 6 \mathrm{dt} 00978 \mathrm{f}$

\$These authors jointly supervised this work.
}

heterogeneous catalysis of cyclopropanation of alkenes using silver foil were reported. ${ }^{6}$ The use of solid-state synthesis of molecular inorganic compounds has also been reported for transition metal complexes, ${ }^{7}$ but rarely for main-group inorganic and organometallic systems, despite one previous example of the mechanochemical synthesis of bis(n-propyltetramethylcyclopentadienyl)strontium ${ }^{8}$ and an aluminium trialkyl complex. ${ }^{9}$ There has been recent interest in highyielding, minimal-waste, and low-energy synthetic routes among the communities of green chemistry and the pharmaceutical and fine chemicals industries. More widespread use of mechanochemistry is increasingly attractive and sustainable since the reactions can be solvent-free, rapid, essentially quantitative, and cost-effective.

Our groups have separately been interested in synthetic main-group chemistry, ${ }^{10}$ and the application of transition metal complexes and metal oxide materials in artificial photosynthesis. ${ }^{11}$ In view of the dearth of studies on main-group complexes in artificial photosynthesis and photoredox chemistry, we sought to develop an atom economical synthetic route for indium complexes that can potentially function as visible light photosensitizers. ${ }^{12}$ Currently, the most popular photosensitizers typically comprise heavy-metals, such as in the case of ruthenium oligopyridine complexes, which undergo metalto-ligand charge transfer (MLCT) transitions and exhibit longlived excited states. ${ }^{12}$ Although indium shares the same period, little has been done to explore its heavy atom effect, which could enhance the rate of intersystem crossing from the photoexcited singlet to the triplet state, and hence significantly prolong the lifetime of the photosensitizer. We were particularly attracted to indium complexes primarily due to their ability to mediate organic reactions ${ }^{13}$ in addition to other attractive attributes such as their low-toxicity, ${ }^{14}$ water tolerance, ${ }^{15}$ and relatively low reduction potential. ${ }^{16}$

Bis(imino)acenaphthene (BIAN) ligands are highly versatile diimine alternatives to the ubiquitous bipyridine and terpyridine derivatives that have frequently been employed as molecular photosensitizers. Functionalized BIAN compounds have been recognized as robust ligands for transition metal centres, 
but are synthetically more accessible than polypyridine compounds, via straightforward condensation reactions between various anilines and acenaphthenequinone. ${ }^{17}$ The combination of the extensive $\pi$-system in the acenaphthene ring and the sterically tunable aniline provides a multitude of customizable $\pi$-acceptor scaffolds, which give us precise synthetic control over electronic and steric properties. A number of transition metal BIAN complexes have been investigated as versatile catalysts for olefin polymerization ${ }^{18}$ and organic reactions like cycloaddition of azides and alkynes. ${ }^{19}$ However, there is only one previous crystallographically characterized example of a monometallic BIAN $^{20}$ and two of tetrakis(imino)pyracene $(\mathrm{TIP})^{21}$ indium(III) complexes.

Here, we report the successful application of mechanochemical milling for both the preparation of BIAN ligands bearing both electron-donating and electron-withdrawing groups - and the subsequent formation of the corresponding indium(III) complexes. These compounds were further characterized for future applications as main-group photosensitizers. $^{22}$ Our novel mechanochemical approach not only allowed us to bypass the use of transition metal reagents during the synthesis of the BIAN ligands, but also provided a more atom efficient, essentially solvent-free, and time-efficient access to such compounds.

Generally, substituted BIAN ligands are synthesized by condensation of acenaphthoquinone with the corresponding aniline under acidic conditions. In many cases, complexation with either $\mathrm{ZnCl}_{2}$ or $\mathrm{NiBr}_{2}$ is required before the removal of the metal ion to furnish the free ligand. ${ }^{23}$ For example, $p$-MeOAr-BIAN (1) and $p$-BrAr-BIAN (2) are synthesized by refluxing acenaphthoquinone with the corresponding aniline in acetic acid in the presence of $\mathrm{ZnCl}_{2}$, followed by de-metallation with $\mathrm{K}_{2} \mathrm{CO}_{3}$ or $\mathrm{Na}_{2} \mathrm{C}_{2} \mathrm{O}_{4}$ (Scheme 1). ${ }^{24}$

Milling acenaphthoquinone with the corresponding aniline in the presence of a catalytic amount of additive ( $p$-anisidine with acetic acid, and $p$-bromoaniline with trifluoroacetic anhydride, for $\mathbf{1}$ and 2, respectively) produced Ar-BIAN ligands, 1 (84\%) and 2 (64\%). This method avoids the use of $\mathrm{ZnCl}_{2}$ as the templating agent and therefore circumvents the need for demetallation (Scheme 2). As a comparison, reactions were performed thermally at $180{ }^{\circ} \mathrm{C}$ in the same reaction vessel without milling. This led to decomposition of both $\mathbf{1}$ and $\mathbf{2}$ during the course of $4 \mathrm{~h}$. Based on the ${ }^{1} \mathrm{H}$ NMR spectra the reaction is almost quantitative (ESI, Fig. S3 and S6 ${ }^{\dagger}$ ) and analytically pure products can be obtained after recrystallization from suitable solvents. The acid-catalyzed mechanochemical synthesis of BIAN ligands described herein presents advantages over established solution-based methods due to short reaction times, vir-

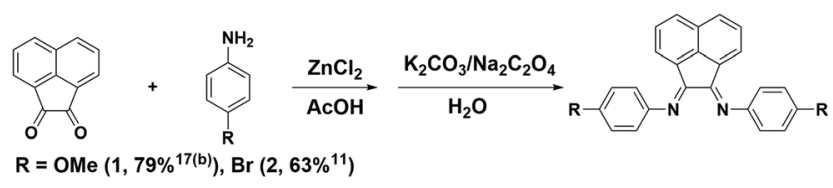

Scheme 1 Zinc-templated synthesis of the Ar-BIAN ligands.

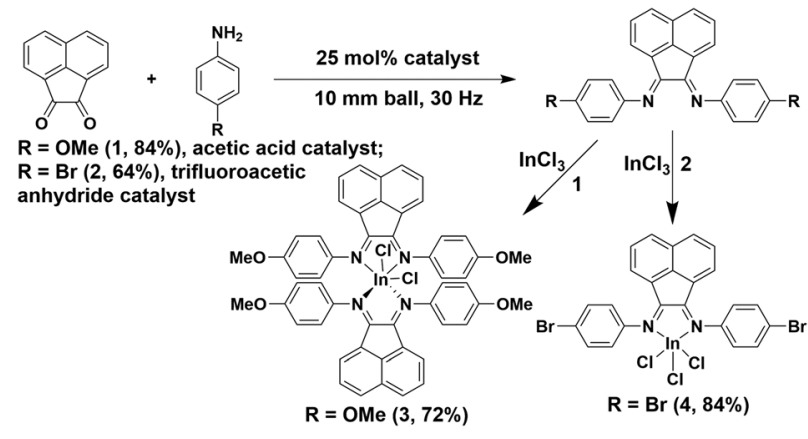

Scheme 2 Mechanochemical synthesis of the Ar-BIAN ligands and indium(III) complexes.

tually solvent-free conditions, and versatility in application to both electron-rich and electron-poor anilines (in $\mathbf{1}$ and 2, respectively). Indium(III) BIAN complexes $p$-MeOAr-BIAN-InCl ${ }_{3}$ $(3,72 \%)$ and $p$-BrAr-BIAN-InCl $3(4,84 \%)$ were obtained by milling equimolar quantities of the corresponding BIAN ligand and $\mathrm{InCl}_{3}$ in a grinder jar equipped with a $10 \mathrm{~mm}$ ball for $40 \mathrm{~min}$ and $2 \mathrm{~h}$, respectively. Similarly, the solid state thermal reactions of neat 1 and 2 with $\mathrm{InCl}_{3}$ at $180{ }^{\circ} \mathrm{C}$ for $2.5 \mathrm{~h}$ without milling led to decomposition products and no reaction was observed in the attempted syntheses of $\mathbf{3}$ and $\mathbf{4}$, respectively. These reaction times represent noticeable improvements from the related previously reported synthesis of $\mathrm{Mes}^{-\mathrm{BIAN}-\mathrm{InCl}_{3}}$ (Mes = mesityl) in THF where the reaction was stirred for 12 hours prior to isolation. ${ }^{20}$

Complexes $\mathbf{3}$ and $\mathbf{4}$ were successfully recrystallized to provide crystals suitable for X-ray structural analyses. Furthermore, all products have been comprehensively characterized by NMR spectroscopy and found to be indistinguishable from those produced by the usual solution methods (ESI, Schemes S7 and S8 $\dagger$ ). Direct formation of the indium(III) complexes by a one-pot process from each crude product of the mechanochemical ligand synthesis was also attempted. In the case of $\mathbf{3}$, complex formation can be identified from the ${ }^{1} \mathrm{H}$ NMR spectrum, which was isolated in 57\% yield after recrystallization. However, in the case of $\mathbf{4}$, the single crystal X-ray data show that 4 was formed, but the ${ }^{1} \mathrm{H}$ NMR spectrum of the crude mixture revealed a mixture of products. The one-pot reaction described herein - without ligand isolation - is a rare example of a multistep mechanochemical synthesis. The previously reported examples typically start from "preformed" ligands and metal complexes ${ }^{25}$ rather than precursors to ligands and metal salts. Our current report thus further raises the orthogonality of multi-step mechanochemical synthesis and widens its applicability.

Both indium(III) complexes adopt distorted octahedral geometries (Fig. 1). The $\mathrm{C}-\mathrm{N}$ and $\mathrm{C}-\mathrm{C}$ bond distances on the diimine framework are consistent with the typical $\mathrm{C}=\mathrm{N}$ and $\mathrm{C}-\mathrm{C}$ bond lengths previously reported. ${ }^{20}$ Therefore each complex consists of neutral BIAN ligands coordinating via dative bonds to the indium(III) metal center. Complex 4 contains only one bound BIAN with $\mathrm{In}-\mathrm{N}$ bond distances of 
(a)

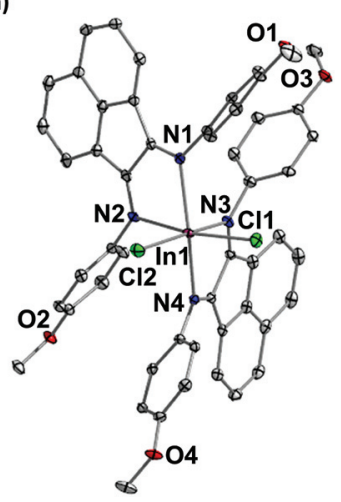

(b)

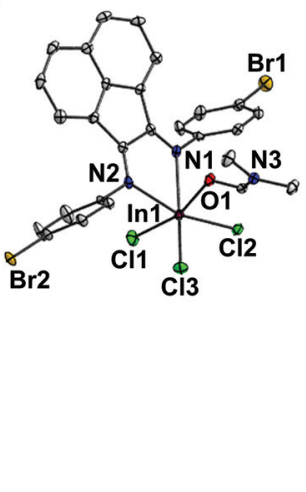

Fig. 1 Thermal ellipsoid plots $(50 \%)$ of (a) $\left[(p-M e O A r-B I A N)_{2} \mathrm{InCl}_{2}\right]^{+}$(3) and (b) ( $p$-BrAr-BIAN) InCl 3 (4) (DMF solvate molecule excluded). Hydrogen atoms have been omitted for clarity. Selected bond lengths ( $\AA$ ): (a) In1-N1 2.296(2), In1-N2 2.324(2), In1-N3 2.311(2), In1-N4 2.323(2), In1Cl1 2.413(5), In1-Cl2 2.396(5). (b) In1-N1 2.390(3), In1-N2 2.301(3), In1Cl1 2.434(9), In1-Cl2 2.419(9), In1-Cl3 2.429(9), In1-O1 2.258(2).

2.390(3) and 2.301(3) A. In contrast, 3 crystallized out as a bis(BIAN) complex, with $\left[\mathrm{InCl}_{4}\right]^{-}$as the counter anion. The average In-N bond distance in 3 (2.313(3) $\AA$ ) is shorter than that measured in 4 (2.346(4) $)$, reflecting the stronger binding and hence more electron rich nature of the imine $\mathrm{N}$ atoms in 3 . The In-Cl bond distances of the bis(BIAN) cation in complex 3 are 2.4126(5) and 2.3963(5) $\AA$ whereas those in complex 4 range from $2.4185(9)$ to $2.4336(9) \AA$. It is interesting to note that the average $\mathrm{In}-\mathrm{Cl}$ bond distance in $\mathbf{3}$ is slightly shorter than that in the related bromo derivative, despite the fact that both are significantly longer than the $\mathrm{In}-\mathrm{Cl}$ distance in $\mathrm{InCl}_{3}(\mathrm{THF})_{3}(2.331(3) \AA) .{ }^{26}$ A lengthening of the $\mathrm{In}-\mathrm{Cl}$ bond distances in our indium(III) complexes is expected due to the increased electron donation from the Ar-BIAN ligands compared to $\mathrm{InCl}_{3}(\mathrm{THF})_{3}$. However, the slight increase of the In-Cl bond distance in $\mathbf{4}$ over that in $\mathbf{3}$ is surprising, and may be due to extra electron density donated by the $\mathrm{N}, \mathrm{N}$-dimethylformamide (DMF) molecule to the metal center.

At $25{ }^{\circ} \mathrm{C}$, the ${ }^{1} \mathrm{H}$ NMR spectrum of 3 displays broadened signals in the aromatic region, which may be the result of cistrans isomerization taking place in solution on the NMR timescale. To understand the behaviour of 3 in solution, variable temperature NMR spectroscopy was carried out in acetone- $\mathrm{d}_{6}$ (ESI, Fig. S7 $\dagger$ ). As the temperature was reduced, the isomerization process slowed down and the signals from the two isomers started to be resolved. Three singlets were observed with an intensity ratio of $1: 1: 1$ at around $4 \mathrm{ppm}$ at $-70{ }^{\circ} \mathrm{C}$. They correspond to the three separate proton environments of the $-\mathrm{OCH}_{3}$ groups in the trans- (one singlet) and cis-isomers (two singlets). In the aromatic region, two sets of signals could be observed below $-60{ }^{\circ} \mathrm{C}$, with one set being assigned to the trans-isomer and the other set to the cis-isomer. According to the integration of the signals, the ratio between the trans and cis isomers varies with temperature. An enthalpy change of $+19.7 \mathrm{~kJ} \mathrm{~mol}^{-1}$ and an entropy change of $+75.8 \mathrm{~J} \mathrm{~mol}^{-1} \mathrm{~K}^{-1}$ for

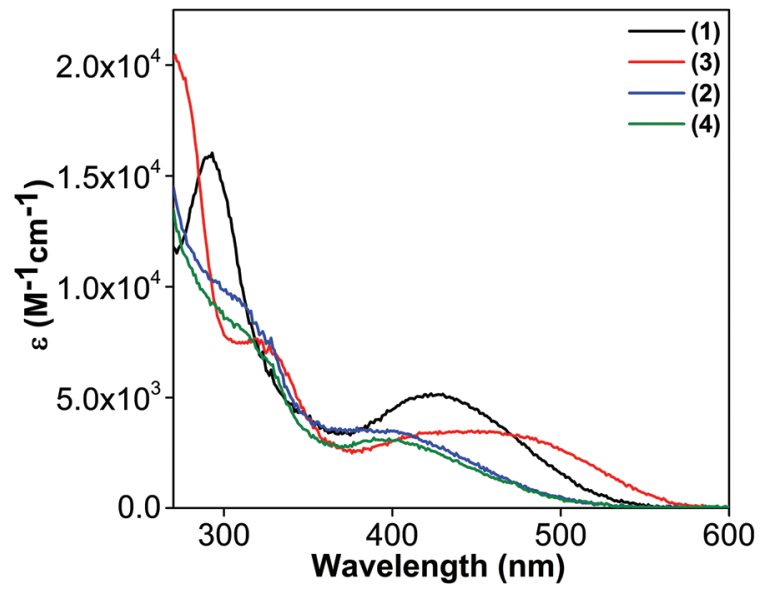

Fig. 2 UV-Vis spectra for 1 in acetonitrile (ACN, black), 3 in ACN (red), 2 in DMF (blue), and 4 in DMF (green).

the cis to trans isomerization were calculated from the Van't Hoff plot (ESI, Fig. S8†).

The UV-vis spectra for both BIAN ligands 1 and 2 and their corresponding indium(III) complexes $\mathbf{3}$ and $\mathbf{4}$ were recorded at $298 \mathrm{~K}$ and are illustrated in Fig. 2. The extinction coefficient decreases when the electron-donating $-\mathrm{OCH}_{3}$ group is replaced by the electron withdrawing $-\mathrm{Br}$ group, consistent with the trend reported by Hasan. ${ }^{17}$ The high energy bands are assigned to the $\pi-\pi^{*}$ ligand-centered transitions between the arylimine and the acenaphthene moieties, whereas the longer wavelength bands are due to the $n-\pi^{*}$ transition from the diimine to the acenaphthene (vide infra). The absorption spectrum of $\mathbf{3}$ is red-shifted in comparison with the free ligand $\mathbf{1}$. However the absorption spectra for $\mathbf{4}$ and the uncoordinated free ligand 2 are very similar. Nevertheless, both the electrochemical studies and the DFT calculations were consistent with the formation of the proposed indium(III) complex (vide infra).

TD-DFT calculations were used to predict the electronic absorption spectra of the complexes isolated. The calculations were carried out with different basis sets (B3LYP/6-31+G* and B3LYP/6-31++ $\mathrm{G}^{* *}$ ) and the spectra have been recorded either under vacuum or with the polarizable continuum model to account for solvent effects. To validate our choice of basis sets, geometry optimizations were performed at the B3LYP/6-31+G* level of theory, with the pseudo potential LANL2DZ for the indium, chlorine, and bromine atoms. The agreement between the experimentally determined and the computed structures supports the method used (Table S11, ESI $\dagger$ ). The calculated predominant contributions to the absorption maximum of complex $3\left(\lambda_{\max }=461 \mathrm{~nm}\right)$ corresponds to electronic transitions from the HOMO $\rightarrow$ LUMO, HOMO-2 $\rightarrow$ LUMO, HOMO-1 $\rightarrow$ LUMO, and HOMO-1 $\rightarrow$ LUMO+1. On the other hand, the visible absorption maximum of complex $4\left(\lambda_{\max }=\right.$ $400 \mathrm{~nm}$ ) corresponds exclusively to the HOMO $\rightarrow$ LUMO transition (see the ESI $\dagger$ ). As illustrated in Fig. 3, the HOMO of 4 consists largely of contributions from the arylimino fragments, whereas the LUMO is delocalized over the atoms of the ace- 


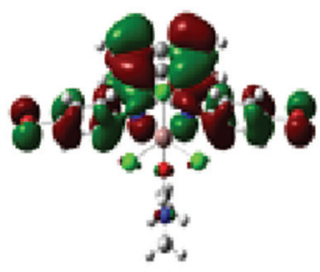

HOMO

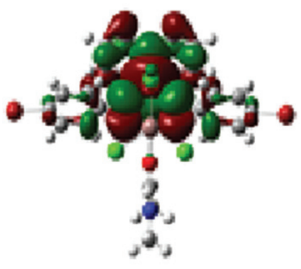

LUMO
Fig. 3 Electron density distributions of the molecular orbitals involved in the UV-Vis spectra for 4 calculated at the B3LYP/6-31+G(d) level of theory.

naphthene and imine moieties. This supports our assignments of the UV-vis spectral bands above.

The electrochemical behavior of both indium complexes at $298 \mathrm{~K}$ was studied using cyclic voltammetry (CV) (Table 1). The voltammograms of 3 in ACN and 4 in DMF are shown in Fig. 4. During the cathodic scan of $\mathbf{4}$, a series of reduction waves were observed between $-1.0 \mathrm{~V}$ to $-2.2 \mathrm{~V}$. The first two reduction waves appeared to be quasi-reversible on the timescale of the experiment. We attribute these first two reduction waves to the reduction of the indium(III) center on $\mathbf{4}$, since this process may involve some structural changes due to the dissociation of $\mathrm{Cl}^{-}$ anions. The third reduction wave occurred at $-1.6 \mathrm{~V}$ and sub-

Table 1 Electrochemical data for complexes 3 and 4

\begin{tabular}{lll}
\hline & $E_{\mathrm{p}}^{\mathrm{ox}} / E_{\mathrm{p}}^{\mathrm{red}}\left(\mathrm{V} v s . \mathrm{Fc}^{+} / \mathrm{Fc}\right)$ & \\
\cline { 2 - 3 } Compound & 3 & 4 \\
\hline Ligand reduction & $-1.02 /-1.13$ & $-1.23 /-1.57$ \\
& $-/-1.74$ & $-2.10 /-2.21$ \\
Ligand oxidation & $-2.17 /-2.29$ & - \\
In(III) reduction & $+1.41 /-$ & - \\
& $+1.75 /-$ & $-0.96 /-1.03$ \\
& $-0.74 /-0.81$ & $-1.26 /-1.29$
\end{tabular}

sequent processes were probably due to reduction of ligand 2 . The anodic processes occurring between $-1.2 \mathrm{~V}$ and $-0.1 \mathrm{~V}$ likely result from re-oxidation of the ligand-bound indium intermediate products.

In the case of 3 in ACN, two irreversible anodic waves were observed at $+1.4 \mathrm{~V}$ and $+1.7 \mathrm{~V}$, which arise from oxidation of the ligand. ${ }^{17}$ During the cathodic scan, a total of six reduction waves were observed but we could not assign the origin for each because of the equilibrium processes of 3 in solution (vide supra). The first reduction at $-0.8 \mathrm{~V}$ is electrochemically reversible with $\Delta E_{\mathrm{p}}=60 \mathrm{mV}$, while the next two reduction waves appear to be chemically reversible. The electrochemical reversibility of the first reduction wave suggested an increased stability of $\left[(p \text {-MeOAr-BIAN })_{2} \mathrm{InCl}_{2}\right]^{+}$, since no reversible redox cycle was observed in 4 .

The voltammograms of both indium(III) complexes show considerably different behavior from their corresponding Ar-BIAN ligand (CV of 2 in DMF in ESI, Fig. S15†; CV of 1 in ACN can be found in ref. 17). In particular, the indium(III) complexes exhibit more reduction waves due to electrochemical processes at the indium(III) center. This indicates that 3 and $\mathbf{4}$ can be readily converted to their indium(I) congeners by using mild reducing agents with reduction potentials between $-1.0 \mathrm{~V}$ to $-2.0 \mathrm{~V}^{27}$

Herein we have introduced an essentially solvent-free, atom-efficient route to the synthesis of Ar-BIAN ligands and their indium(III) complexes through a mechanochemical milling approach. This methodology circumvents the $\mathrm{ZnCl}_{2}$ templating step frequently used in the synthesis of Ar-BIAN ligands, and reduces the reaction time for the synthesis of the indium(III) complexes. This protocol can be generally applied to electron-donating and electron-withdrawing variants of the BIAN ligands and complexes. Both complexes absorb visible light, although the complex bearing the -OMe group absorbs further in the red region. The electrochemical studies support the feasibility of reduction of the indium(III) complexes to their indium(I) derivatives, both of which will be investigated as potential photosensitizers in the future. (a)

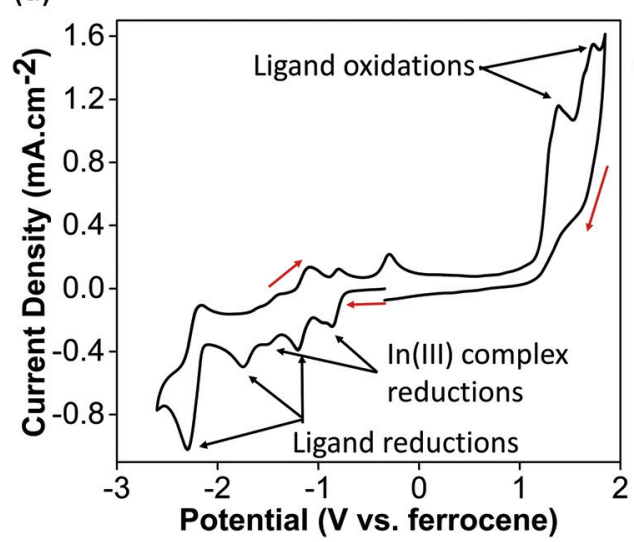

(b)

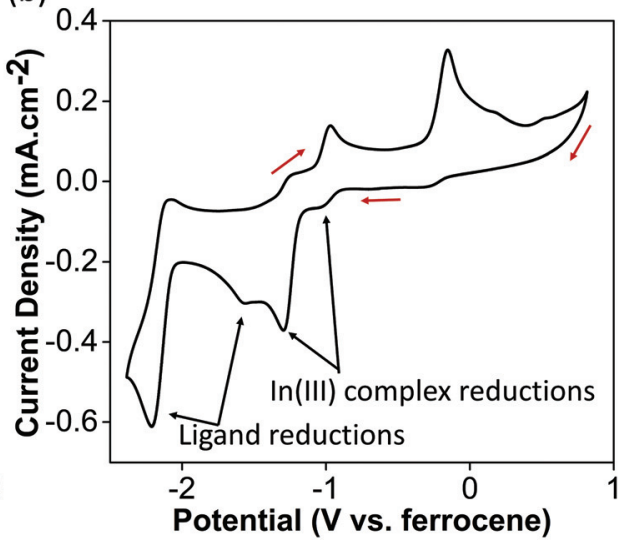

Fig. 4 Cyclic voltammograms of (a) 3 in ACN solution and (b) 4 in DMF solution at $298 \mathrm{~K}$ with $0.10 \mathrm{M}\left(n \mathrm{Bu}_{4} \mathrm{~N}\right) \mathrm{PF}_{6}$ as the supporting electrolyte and glassy carbon ( $3 \mathrm{~mm}$ in diameter) as the working electrode. All potentials reported are referenced to $\mathrm{Fc}^{+} / \mathrm{Fc}$. Scan rate: $100 \mathrm{mV} \mathrm{s}$. 
F. G. would like to thank the NTU start-up grant (M4080552) and the MOE Tier 1 grant (M4011441) for financial support. H. S. S. is supported by a NTU start-up grant (M4081012), a MOE Tier 1 grant (M4011144), and the Nanyang Assistant Professorship (M4081154). H. S. S. also thanks the Solar Fuels Laboratory at NTU and the Singapore-Berkeley Research Initiative for Sustainable Energy (SinBeRISE) CREATE Programme.

\section{References}

1 (a) E. Boldyreva, Chem. Soc. Rev., 2013, 42, 7719-7738; (b) N. R. Rightmire and T. P. Hanusa, Dalton Trans., 2016, 45, 2352-2362.

2 C. X. Cui, J. Su and R. H. Baughman, Method for the mechanochemical preparation of high performance ferroelectric ceramics, US pat, US6136229A, 2000.

3 (a) V. Sepelak, A. Duvel, M. Wilkening, K.-D. Becker and P. Heitjans, Chem. Soc. Rev., 2013, 42, 7507-7520; (b) C. Suryanarayana, Prog. Mater. Sci., 2001, 46, 1-184; (c) S. L. James, et al., Chem. Soc. Rev., 2012, 41, 413447.

4 (a) P. Balaz, et al., Chem. Soc. Rev., 2013, 42, 7571-7637; (b) T. K. Purkait, Ph.D. thesis, Tulane University, 2013.

5 (a) M. R. Caira, L. R. Nassimbeni and A. F. Wildervanck, J. Chem. Soc., Perkin Trans. 2, 1995, 2213-2216; (b) M. C. Etter and D. A. Adsmond, J. Chem. Soc., Chem. Commun., 1990, 589-591; (c) M. C. Etter, Z. UrbanczykLipkowska, M. Zia-Ebrahimi and T. W. Panunto, J. Am. Chem. Soc., 1990, 112, 8415-8426; (d) A. O. Patil, D. Y. Curtin and I. C. Paul, J. Am. Chem. Soc., 1984, 106, 348-353; (e) V. R. Pedireddi, W. Jones, A. P. Chorlton and R. Docherty, Chem. Commun., 1996, 987-988; (f) F. Toda, K. Tanaka and A. Sekikawa, J. Chem. Soc., Chem. Commun., 1987, 279-280.

6 L. Chen, M. O. Bovee, B. E. Lemma, K. S. M. Keithley, S. L. Pilson, M. G. Coleman and J. Mack, Angew. Chem., Int. Ed., 2015, 54, 11084-11087.

7 (a) C. J. Adams, M. A. Kurawa, M. Lusi and A. G. Orpen, CrystEngComm, 2008, 10, 1790-1795; (b) V. P. Balema, J. W. Wiench, M. Pruski and V. K. Pecharsky, Chem. Commun., 2002, 1606-1607; (c) G. A. Bowmaker, N. Chaichit, C. Pakawatchai, B. W. Skelton and A. H. White, Dalton Trans., 2008, 2926-2928; (d) G. A. Bowmaker, B. W. Skelton and A. H. White, Inorg. Chem., 2009, 48, 3185-3197; (e) T. Chen, B. Liang and X. Xin, J. Solid State Chem., 1997, 132, 291-293; $(f)$ G. Hihara, M. Satoh, T. Uchida, F. Ohtsuki and H. Miyamae, Solid State Ionics, 2004, 172, 221-223; (g) P. J. Nichols, C. L. Raston and J. W. Steed, Chem. Commun., 2001, 1062-1063; (h) D. N. T. Ohshita, A. Tsukamoto, N. Tsuchiya, T. Isobe and N. Y. A. H. I. M. Senna, Ann. Chim. Sci. Mater., 2002, 27, 91-101; (i) S. K. Thabet, H. A. Tayim and M. U. Karkanawi, Inorg. Nucl. Chem. Lett., 1972, 8, 211-213; (j) X. Yao, L. Zheng and X. Xin, J. Solid State Chem., 1995,
117, 333-336; ( $k$ ) A. Kobayashi, T. Hasegawa, M. Yoshida and M. Kato, Inorg. Chem., 2016, 55, 1978-1985.

8 D. W. Peters and R. G. Blair, Faraday Discuss., 2014, 170, 83-91.

9 N. R. Rightmire, T. P. Hanusa and A. L. Rheingold, Organometallics, 2014, 33, 5952-5955.

10 (a) Y. X. Shi, R. Z. Liang, K. A. Martin, D. G. Star, J. Diaz, X. Y. Li, R. Ganguly and F. Garcia, Chem. Commun., 2015, 51, 16468-16471; (b) Y. X. Shi, R. Z. Liang, K. A. Martin, N. Weston, S. Gonzalez-Calera, R. Ganguly, Y. Li, Y. Lu, A. J. M. Ribeiro, M. J. Ramos, P. A. Fernandes and F. García, Inorg. Chem., 2015, 54, 6423-6432; (c) M. Wu. M, A. M. Gill, L. Yunpeng, L. Falivene, L. Yongxin, R. Ganguly, L. Cavallo and F. Garcia, Dalton Trans., 2015, 44, 1516615174.

11 (a) A. Agiral, H. S. Soo and H. Frei, Chem. Mater., 2013, 25, 2264-2273; (b) S. Gazi, W. K. H. Ng, R. Ganguly, A. M. P. Moeljadi, H. Hirao and H. S. Soo, Chem. Sci., 2015, 6, 7130-7142; (c) H. S. Soo, A. Agiral, A. Bachmeier and H. Frei, J. Am. Chem. Soc., 2012, 134, 17104-17116; (d) S. K. Muduli, S. Wang, S. Chen, C. F. Ng, C. H. A. Huan, T. C. Sum and H. S. Soo, Beilstein J. Nanotechnol., 2014, 5, 517-523; (e) H. Shao, S. K. Muduli, P. D. Tran and H. S. Soo, Chem. Commun., 2016, 52, 2948-2951; ( $f$ ) H. S. Soo, A. C. Komor, A. T. Iavarone and C. J. Chang, Inorg. Chem., 2009, 48, 10024-10035; $(g)$ H. S. Soo, M. L. Macnaughtan, W. W. Weare, J. Yano and H. M. Frei, J. Phys. Chem. C, 2011, 115, 24893-24905; (h) H. S. Soo, M. T. Sougrati, F. Grandjean, G. J. Long and C. J. Chang, Inorg. Chim. Acta, 2011, 369, 82-91; (i) J. W. Kee, Y. Y. Ng, S. A. Kulkarni, S. K. Muduli, K. Xu, R. Ganguly, Y. Lu, H. Hirao and H. S. Soo, Inorg. Chem. Front., 2016, 3, DOI: $10.1039 / \mathrm{C} 5 \mathrm{QI00221D,} \mathrm{Adv.} \mathrm{Article.}$

12 A. Juris, V. Balzani, F. Barigelletti, S. Campagna, P. Belser and A. von Zelewsky, Coord. Chem. Rev., 1988, 84, 85-277.

13 P. Cintas, Synlett, 1995, 1087-1096.

14 L. A. Paquette, in Green Chemistry. Frontiers in Benign Chemical Synthesis and Processes, ed. P. T. Anastas and T. C. Williamson, Oxford University Press, Oxford, 1998, 250.

15 J. Podlech and T. C. Maier, Synthesis, 2003, 0633-0655.

16 C. J. Li and T. H. Chan, Tetrahedron Lett., 1991, 32, 70177020.

17 K. Hasan and E. Zysman-Colman, J. Phys. Org. Chem., 2013, 26, 274-279.

18 M. Shiotsuki, P. S. White, M. Brookhart and J. L. Templeton, J. Am. Chem. Soc., 2007, 129, 4058-4067.

19 L. Li, P. S. Lopes, V. Rosa, C. A. Figueira, M. A. N. D. A. Lemos, M. T. Duarte, T. Aviles and P. T. Gomes, Dalton Trans., 2012, 41, 5144-5154.

20 N. J. Hill, G. Reeske, J. A. Moore and A. H. Cowley, Dalton Trans., 2006, 4838-4844.

21 K. V. Vasudevan and A. H. Cowley, New J. Chem., 2011, 35, 2043-2046. 
22 (a) L. A. Cameron, J. W. Ziller and A. F. Heyduk, Chem. Sci., 2016, 7, 1807-1814; (b) D. A. Evans, L. M. Lee, I. VargasBaca and A. H. Cowley, Organometallics, 2015, 34, 24222428; (c) W. W. Kramer, L. A. Cameron, R. A. Zarkesh, J. W. Ziller and A. F. Heyduk, Inorg. Chem., 2014, 53, 88258837.

23 F. Ragaini, S. Cenini, S. Tollari, G. Tummolillo and R. Beltrami, Organometallics, 1999, 18, 928-942.

24 (a) A. L. Gottumukkala, J. F. Teichert, D. Heijnen, N. Eisink, S. van Dijk, C. Ferrer, A. van den Hoogenband and A. J. Minnaard, J. Org. Chem., 2011, 76, 3498-3501; (b) C. S. K. Mak, H. L. Wong, Q. Y. Leung, W. Y. Tam, W. K. Chan and A. B. Djurišić, J. Organomet. Chem., 2009, 694, 2770-2776.

25 (a) E. H. H. Chow, F. C. Strobridge and T. Friščić, Chem. Commun., 2010, 46, 6368-6370; (b) J. G. Hernández, I. S. Butler and T. Friščić, Chem. Sci., 2014, 5, 35763582.

26 B. R. Whittlesey and I. P. Ittycheriah, Acta Crystallogr., Sect. C: Cryst. Struct. Commun., 1994, 50, 693-695.

27 N. G. Connelly and W. E. Geiger, Chem. Rev., 1996, 96, 877910. 